\title{
Dual-Layer Spectral CTA for TAVI Planning Using a Split-Phase Protocol and Low-keV Virtual Monoenergetic Images: Improved Image Quality in Comparison with Single-Phase Conventional CTA Verbesserte Bildqualität der TAVI-CTA eines Dual-Layer Spektral-CTs unter Verwendung eines Zwei-Phasen-Protokolls und virtuell- monoenergetischer Bilder im Vergleich zu einem konventionellen CT
}

Authors

David Mangold $^{10}$, Janek Salatzki², Johannes Riffel ${ }^{2}$, Hans-Ulrich Kauczor ${ }^{1}$, Tim Frederik Weber ${ }^{1}$

Affiliations

1 Department of Diagnostic and Interventional Radiology, University Hospital Heidelberg, Germany

2 Department of Internal Medicine III, University Hospital Heidelberg, Germany

Key words

transcatheter aortic valve implantation (TAVI), transcatheter aortic valve replacement (TAVR), dual-energy CT, spectral detector $\mathrm{CT}$, aortography, virtual monoenergetic imaging

received 03.08.2021

accepted 18.11.2021

published online 28.12.2021

Bibliography

Fortschr Röntgenstr 2022; 194: 652-659

DOI 10.1055/a-1717-2542

ISSN 1438-9029

(c) 2021. Thieme. All rights reserved.

Georg Thieme Verlag KG, Rüdigerstraße 14,

70469 Stuttgart, Germany

Correspondence

David Mangold

Department of Diagnostic and Interventional Radiology,

University Hospital Heidelberg, INF 420, 69120 Heidelberg, Germany

Tel.: +49/62215634141

david.mangold@med.uni-heidelberg.de

\section{ZUSAMMENFASSUNG}

Ziel Die Anpassung der CT-Protokolle zur TAVI-Planung (Transkatheter-Aortenklappen-Implantation) ist erforderlich, wenn ein Dual-Layer Spektral-CT (DLCT) der ersten Generation verwendet wird. Ziel dieser Studie war es, die objektive Bildqualität der CT-Angiografie (CTA), die mit einem DLCT angefertigt wurden, zu bewerten. Untersucht wurden diesbezüglich virtuell monoenergetische Bilder bei $40 \mathrm{keV}$ (40 keVVMI) eines Zwei-Phasen-Protokolls. Zum Vergleich dienten CTA, die mit dem einphasigen Protokoll eines konventionellen CTs (SLCT) angefertigt wurden.
Material und Methoden 75 CTAs des DLCT wurden retrospektiv mit 75 CTAs eines konventionellen CTs verglichen. Mit dem DLCT wurde die CTA ohne EKG-Synchronisation unmittelbar nach einer retrospektiv EKG-gegateten Aufnahme des Herzens und des Aortenbogens durchgeführt. Mit dem SLCT wurde eine einphasige CTA durchgeführt, welche sowohl das Herz als auch die Zugangsgefäße in einem retrospektiv EKG-synchronisierten Scan erfasste. Die objektive Bildqualität wurde auf verschiedenen Ebenen des arteriellen Zugangsweges verglichen.

Ergebnisse Die virtuell monoenergetischen Bilder des DLCT bei $40 \mathrm{keV}$ zeigten eine signifikant höhere absolute CT-Zahl, SNR und CNR auf allen Ebenen des arteriellen Zugangswegs. Bei den $40 \mathrm{keV-VMI}$ der DLCT betrug das durchschnittliche aortale Gefäßsignal aller 6 gemessenen Regionen 589,6 $243 \mathrm{HU}$ im Vergleich zu 492,7 \pm 209 HU des SLCT $(p<0,01)$. Ein ähnlicher Trend konnte für SNR $(23,6 \pm 18$ vs. $18,6 \pm 9 ; p<0,01)$ und CNR $(21,1 \pm 18$ vs. $16,4 \pm 8 ; p<0,01)$ beobachtet werden. Für das Signalrauschen wurden keine signifikanten Unterschiede beobachtet (27,8 $\pm 9 \mathrm{HU}$ vs. $28,1 \pm 8 \mathrm{HU}$; $\mathrm{p}=0$,599).

Schlussfolgerung Bei der TAVI-Planung kann unter Verwendung eines DLCT mit einem Zwei-Phasen-Protokoll und $40 \mathrm{keV}-\mathrm{VMI}$ eine höhere objektive Bildqualität im Vergleich zu einem einphasigen Protokoll eines konventionellen CTScanners erzielt werden.

\section{Kernaussagen:}

- Bei Verwendung eines Dual-Layer-CT der ersten Generation kann eine Anpassung der CT-Protokolle zur TAVI-Planung erforderlich sein.

- Die Rekonstruktion virtuell-monoenergetischer Bilder bei $40 \mathrm{keV}$ verbessert die Bildqualität.

- Bei einem Zwei-Phasen-Protokoll ist die Strahlendosis geringer im Vergleich zu einer einphasigen EKG-gegateten CT-Akquisition.

\section{ABSTRACT}

Purpose Adaptation of computed tomography protocols for transcatheter aortic valve implantation (TAVI) planning is required when a first-generation dual-layer spectral CT scanner (DLCT) is used. The purpose of this study was to evaluate the 
objective image quality of aortic CT angiography (CTA) for TAVI planning using a split-phase technique with reconstruction of $40 \mathrm{keV}$ virtual monoenergetic images (40 keV-VMI) obtained with a DLCT scanner. CT angiography obtained with a single-phase protocol of a conventional single-detector CT (SLCT) was used for comparison.

Materials and Methods 75 CTA scans from DLCT were retrospectively compared to 75 CTA scans from SLCT. For DLCT, spiral CTA without ECG-synchronization was performed immediately after a retrospectively ECG-gated acquisition covering the heart and aortic arch. For SLCT, spiral CTA with retrospective ECG-gating was performed to capture the heart and the access route simultaneously in one scan. Objective image quality was compared at different levels of the arterial access route.

Results $40 \mathrm{keV}$ virtual monoenergetic images of DLCT showed a significantly higher mean vessel attenuation, SNR, and CNR at all levels of the arterial access route. With $40 \mathrm{keV}$-VMI of DLCT, the overall mean aortic attenuation of all six measured regions was $589.6 \pm 243 \mathrm{HU}$ compared to $492.7 \pm 209 \mathrm{HU}$ of SLCT $(\mathrm{p}<0.01)$. A similar trend could be observed for SNR $(23.6 \pm 18$ vs. $18.6 \pm 9 ; \mathrm{p}<0.01)$ and CNR $(21.1 \pm 18$ vs. $16.4 \pm 8 ; \mathrm{p}<0.01)$.
No deterioration was observed for vascular noise $(27.8 \pm 9 \mathrm{HU}$ vs. $28.1 \pm 8 \mathrm{HU} ; \mathrm{p}=0.599$ ).

Conclusion Using a DLCT scanner with a split-phase protocol and $40 \mathrm{keV}-\mathrm{VMI}$ for TAVI planning, higher objective image quality can be obtained compared to a single-phase protocol of a conventional CT scanner.

\section{Key Points:}

- Adaption of TAVI planning CT protocols may be required when using a first-generation dual-layer CT scanner.

- Reconstruction of virtual monoenergetic images at $40 \mathrm{keV}$ improves image quality.

- With a split-phase protocol, the radiation dose is lower compared to a single-phase ECG-gated CT acquisition.

\section{Citation Format}

- Mangold D, Salatzki J, Riffel J et al. Dual-Layer Spectral CTA for TAVI Planning Using a Split-Phase Protocol and Low-keV Virtual Monoenergetic Images: Improved Image Quality in Comparison with Single-Phase Conventional CTA. Fortschr Röntgenstr 2022; 194: 652-659

\section{Introduction}

Dual-energy computed tomography (DECT) has been implemented successfully in clinical practice. There are different technical approaches to acquire spectral imaging, but they all use a high and low mean energy $\mathrm{X}$-ray spectrum from one examination to obtain images. A widespread concept is a dual-source system with two orthogonally positioned X-ray tubes and detectors rotating simultaneously. Another approach is $k V_{p}$ switching, in which an $X$-ray tube rapidly switches between low and high energy levels at each X-ray projection [1, 2]. A recently developed CT technology is a detector-based DECT using a polychromatic X-ray tube and two layers of detectors - dual-layer detector computed tomography (DLCT). The top layer, an yttrium-based garnet scintillator, and the second gadolinium-oxysulphide-based layer absorb low and high energy photons separately [3, 4].

The first-generation DLCT scanner is equipped with a detector with a width of $4 \mathrm{~cm}$ along the z-axis. The use of a CT scanner with such detector coverage may cause difficulties in ECG synchronous cardiac imaging [5-7]. Due to its special requirements (CT angiography of the vascular access and an ECG-synchronized data set of the aortic root and heart), the scan protocols for TAVI planning have to be adapted when using a scanner with a smaller detector width $[6,8]$. At our institution, according to the recommendations for CT scanners with a limited detector coverage, we chose a split-phase protocol for TAVI planning.

After a retrospective ECG-gated scan of the annulus including the heart and the aortic arch, the access vasculature is evaluated in a second scan without ECG synchronization [8]. This split-phase protocol requires a short intermission between the two scans to make scan adjustments and adjust the table position resulting in a late arterial acquisition. Caused by the lower vessel attenuation of the late arterial phase compared to an early arterial phase, this split-phase protocol could lead to a loss of image quality in the evaluation of the arterial access route. However, DLCT allows for increasing vessel attenuation in contrast-enhanced CT scans using virtual monoenergetic image reconstructions (VMI) at lower energy levels to compensate for this effect of suboptimal vessel enhancement [9-12].

The primary objective of this study was to determine the objective image quality of DLCT in CTA for TAVI planning. To this end, we compared low-energy (40 keV) VMI of DLCT with conventional images $(\mathrm{Cl})$ obtained with single-layer CT. Absolute CT attenuation values, noise, signal-to-noise ratio (SNR), and contrast-to-noise ratio (CNR) were compared across six levels of the arterial access pathway.

Secondary objectives of this study were to assess the percentage of CTAs with sufficient contrast enhancement and the radiation dose during TAVI planning between DLCT and SLCT. According to recent recommendations, sufficient contrast enhancement was defined as the presence of a CT attenuation value of at least $250 \mathrm{HU}$ across all six levels of the arterial access pathway [5, 8].

\section{Materials and Methods}

\section{Study design}

Until 2017, an SLCT scanner was used for TAVI planning at our institution. This CT scanner was replaced by a DLCT scanner in December 2017. For our study we included a total of 150 patients who underwent CTA prior to TAVI (75 each for SLCT and DLCT). The included patients were examined in the period from July 
2017 to November 2017 (SLCT) and from January to November 2018 (DLCT). Patients that were scanned during these time periods and had incomplete image data or artifacts caused by metal implants were primarily excluded (SLCT: $n=3$; DLCT: $n=2$ ).

This retrospective single-center study was approved by our local ethics committee with a waiver of written informed consent (Ref. S-620/2018). This study has been performed in accordance with the ethical standards laid down in the 1964 Declaration of Helsinki and its later amendments.

\section{Image acquisition}

\section{SLCT}

Conventional CTA was performed using a Philips Brilliance iCT device providing 128 detector rows on a single-layer detector with a width of $8 \mathrm{~cm}$ (Philips; Best; The Netherlands). The TAVI planning protocol was an ECG-gated spiral acquisition of the heart and total aorta including the access route. The examination was performed with the following parameters: BMI-dependent tube voltage (100 kVp or $120 \mathrm{kVp}$ ) and effective tube current ( $481 \mathrm{mAs}$ or $499 \mathrm{mAs}$ ); rotation time $0.37 \mathrm{~s}$; detector collimation $128 \times 0.625 \mathrm{~mm}$; helical pitch value 0.3 . Using a flying $z$-focus, 256 slices were acquired simultaneously. In patients with a BMI $>25 \mathrm{~kg} / \mathrm{m}^{2}$, the higher tube voltage and effective tube current were chosen. The total scan time was $12.5 \mathrm{~s}$. Bolus tracking was used for image acquisition timing. The acquisition started $11 \mathrm{~s}$ after reaching a contrast enhancement threshold of 150 Hounsfield Units (HU) above the baseline attenuation in the descending aorta.

\section{DLCT}

Spectral CTA was performed using a Philips iQon device providing 64 detector rows on a dual-layer detector with a width of $4 \mathrm{~cm}$ (Philips; Best; The Netherlands). The TAVI planning protocol consisted of a split-phase acquisition of the heart on the one hand and of the total aorta including the access route on the other hand. An ECG-gated spiral acquisition of the heart and aortic arch in caudocranial direction was immediately followed by a late arterial nonECG-gated high-pitch spiral CTA scan from subclavian to femoral arteries in cranio-caudal direction ( $\triangleright$ Fig. 1$)$. The following scanning parameters were used for the late arterial CTA scan: tube voltage $120 \mathrm{kVp}$; effective tube current $130 \mathrm{mAs}$, rotation time $0.27 \mathrm{~s}$; detector collimation $64 \times 0.625 \mathrm{~mm}$; helical pitch value 1.234. Using a flying z-focus, 128 slices were acquired simultaneously. Bolus tracking was used for image acquisition timing. The ECG-gated acquisition of the heart and annulus was started $6 \mathrm{~s}$ after the attenuation reached a contrast enhancement threshold of $110 \mathrm{HU}$ above the baseline in the descending aorta (scan time: 9 seconds). The cranio-caudal acquisition of the CTA was started $26 \mathrm{~s}$ after reaching the threshold value in the descending aorta. The total acquisition time of the late arterial CTA was $3.2 \mathrm{~s}$. In $>$ Table 1 , the relevant scan parameters of both CT protocols are provided.

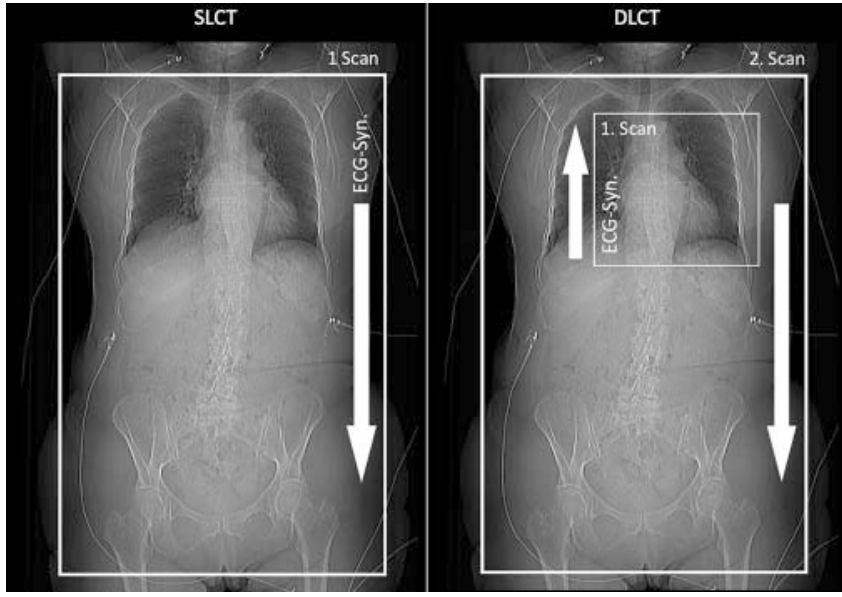

- Fig. 1 Scanning protocols: For SLCT a retrospective ECG-gated spiral acquisition of the heart and the access route was performed in the caudo-cranial direction. For DLCT we used a split protocol with retrospective ECG-gated helical acquisition of the heart and aortic arch in the caudo-cranial direction, immediately followed by a cranio-caudal CTA scan covering the arterial access vasculature.

- Abb. 1 Untersuchungsprotokolle: Mit dem konventionellen CT wurde eine retrospektiv EKG-gegatete Spiralakquisition des Herzens und der Zugangsgefäße in caudo-cranialer Richtung durchgeführt. Mit dem DLCT verwendeten wir ein Zwei-Phasen-Protokoll mit retrospektiv EKG-synchronisiertem Scan des Herzens und des Aortenbogens in kaudo-kranialer Richtung, unmittelbar gefolgt von einem kranio-kaudalen Scan zur Erfassung der arteriellen Zugangsgefäße.

- Table 1 Scanning parameters for aortography of both SLCT and DLCT.

- Tab. 1 Untersuchungsparameter der CT-Angiografie mit dem SLCT sowie mit dem DLCT.

\begin{tabular}{|l|l|l|l|}
\hline Scanning parameters & $\begin{array}{l}\text { SLCT } \\
\text { (BMI <25) }\end{array}$ & $\begin{array}{l}\text { SLCT } \\
\text { (BMI > 25) }\end{array}$ & DLCT \\
\hline Peak tube voltage $\mathrm{kpV}$ & $100 \mathrm{kV}$ & $120 \mathrm{kV}$ & $120 \mathrm{kV}$ \\
\hline Effective tube current & $481 \mathrm{mAs}$ & $499 \mathrm{mAs}$ & $130 \mathrm{mAs}$ \\
\hline Detector collimation & $128 \times 0.625 \mathrm{~mm}$ & $64 \times 0.625 \mathrm{~mm}$ \\
\hline Detector width (z-axis) & $8 \mathrm{~cm}$ & $4 \mathrm{~cm}$ \\
\hline Gantry rotation time & $0.37 \mathrm{~s}$ & $0.27 \mathrm{~s}$ \\
\hline Pitch & $0.3 \mathrm{~s}$ & $1.234 \mathrm{~s}$ \\
\hline Scan time & $12.5 \mathrm{~s}$ & $3.2 \mathrm{~s}$ \\
\hline $\begin{array}{l}\text { Delay of the CTA after } \\
\text { reaching threshold }\end{array}$ & $11 \mathrm{~s}$ & $26 \mathrm{~s}$ \\
\hline $\begin{array}{l}\text { Reconstructed slice } \\
\text { thickness/increment }\end{array}$ & $0.67 \times 0.3 \mathrm{~mm}$ & $0.8 \times 0.4 \mathrm{~mm}$ \\
\hline
\end{tabular}

\section{Contrast medium}

$80 \mathrm{ml}$ of the contrast medium lomeron 400 (400 mg iodine/ml; Bracco Imaging; Konstanz, Germany) was used as the standard volume and was adjusted for obese patients (up to $100 \mathrm{ml}$; mean BMI: $34 \pm 5 \mathrm{~kg} / \mathrm{m}^{2}$ ). The following injection protocol for both scan- 
ners was applied using an automated injector: $4.0 \mathrm{ml} / \mathrm{s}$ for $10 \mathrm{~s}$ $(40 \mathrm{ml})$, followed by $3.0 \mathrm{ml} / \mathrm{s}$ for $13 \mathrm{~s}(40 \mathrm{ml})$ and a saline chaser flush $(50 \mathrm{ml})$.

\section{Image reconstruction}

For SLCT, conventional polychromatic images were reconstructed with a slice thickness of $0.67 \mathrm{~mm}$ and an increment of 0.3 in axial orientation using a standard soft tissue kernel. The images were reconstructed at $70 \%$ of the R-R interval (during diastole). For late arterial DLCT CTA, virtual monoenergetic images (40 keV$\mathrm{VMI}$ ) were reconstructed with a slice thickness of $0.8 \mathrm{~mm}$ and an increment of $0.4 \mathrm{~mm}$ using a standard soft tissue kernel. For both data sets, an iterative reconstruction algorithm was used as provided by the vendor (SLCT: IMR Level 1; DLCT: iDose4 Level 3).

\section{Image analysis}

Objective image quality measurements of both groups were performed by one reader using a dedicated image processing workstation (IntelliSpace Portal Version 10; Philips; Best; The Netherlands). In each CTA, a circular region-of-interest (ROI) with a fixed area of $2.0 \mathrm{~cm}^{2}$ was placed at the following six levels of the aorto-iliac access: ascending aorta (AA) and descending aorta (DA) at the level of the right pulmonary artery, abdominal aorta at the level of the hiatus (HA) and at the level of the renal arteries (RA), right common iliac artery $(\mathrm{RCl})$ and right distal external iliac artery (REI). For calculating the contrast-to-noise ratio (CNR), a circular ROI was placed over the right psoas muscle. The vessel attenuation was defined by the mean enhancement within the $\mathrm{ROI}$ and noise was represented by standard deviation (SD). The signal-to-noise ratio (SNR) was defined as the vessel attenuation divided by noise. The CNR was calculated as follows: $C N R=$ (mean arterial attenuation-mean muscle attenuation)/mean arterial noise.

\section{Statistical analysis}

All data were analyzed using SPSS version 25.0 (SPSS Inc, Chicago, IL, USA). Continuous variables were reported as the mean \pm standard deviation (SD), categorical values as proportions. Wilcoxon ranksum test and two-sample t-test were used to compare continuous variables. All reported $\mathrm{p}$-values are two-sided and a p-value $<0.05$ was considered to indicate statistical significance.

\section{Results}

\section{Patient characteristics}

150 patients ( 72 males; mean age: $82 \pm 6 y$; BMI $28 \pm 5 \mathrm{~kg} / \mathrm{m}^{2}$ ) who underwent CTA prior to TAVI were included in this study (75 on each CT scanner). Age, BMI, and serum creatinine were assessed using electronic medical records. There were no statistical differences in gender, age, or BMI between these two groups as provided in - Table 2. In the SLCT group, 49 CT acquisitions were performed at $120 \mathrm{kV}$ and $26 \mathrm{CT}$ acquisitions at $100 \mathrm{kV}$.
- Table 2 Patient characteristics of the study population (data are means \pm standard deviation).

- Tab. 2 Patientencharakteristika der Studienpopulation (angegeben als Mittelwert \pm Standardabweichung).

\begin{tabular}{|l|l|l|l|}
\hline Patient characteristics & DLCT & SLCT & p-value \\
\hline Male gender & $37(49 \%)$ & $35(47 \%)$ & \\
\hline Age (years) & $81 \pm 6$ & $82 \pm 6$ & 0.334 \\
\hline Weight $(\mathrm{kg})$ & $76 \pm 16$ & $75 \pm 17$ & 0.798 \\
\hline Height $(\mathrm{m})$ & $166 \pm 10$ & $166 \pm 9$ & 0.993 \\
\hline BMI $\left(\mathrm{kg} / \mathrm{m}^{2}\right)$ & $28 \pm 5$ & $27 \pm 5$ & 0.733 \\
\hline Serum creatinine (mg/dl) & $1.1 \pm 0.5$ & $1.2 \pm 0.7$ & 0.375 \\
\hline
\end{tabular}

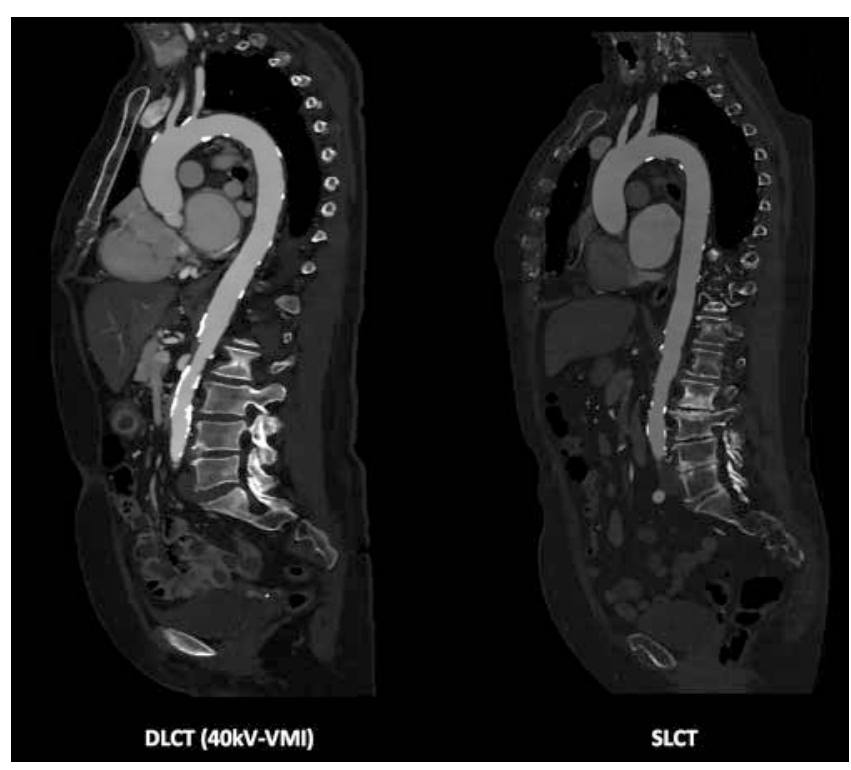

- Fig. 2 40keV-VMI obtained with DLCT compared to conventional SLCT images.

- Abb. 2 Virtuell monoenergetische Rekonstruktion bei $40 \mathrm{keV}$ des DLCT im Vergleich zu einem konventionellen Scan des SLCT.

\section{Quantitative assessment}

Representative images of $40 \mathrm{keV}$ VMI of DLCT and conventional images of SLCT are seen in > Fig. 2. $40 \mathrm{keV} \mathrm{VMI} \mathrm{of} \mathrm{DLCT} \mathrm{showed}$ a significantly higher mean vessel attenuation at all six levels of the arterial access route ( $>$ Table $3 ;>$ Fig. 3 ). The overall mean aortic attenuation of all six measured regions was $589.6 \pm 243$ for DLCT and $492.7 \pm 209$ for SLCT $(p<0.01)$. Similar observations were found for SNR and CNR ( $\vee$ Table 4). The overall mean SNR was $23.6 \pm 18$ for DLCT and $18.6 \pm 9$ for SLCT $(p<0.01)$. The CNR across all segments was $21.1 \pm 18$ for DLCT and $16.4 \pm 8$ for SLCT $(p<0.01)$. No deterioration was found for vessel noise using DLCT ( $\vee$ Table 5). Sufficient aortic enhancement at all segments of the access route was achieved in $93 \%$ with DLCT and $89 \%$ with SLCT. 
- Table 3 Vessel attenuation of $40 \mathrm{keV}$-VMI of DLCT and SLCT (AA: ascending aorta at the level of the right pulmonary artery; DA: descending aorta at the level of the right pulmonary artery; HA: aorta at the level of hiatus; RA: aorta at the level of the renal arteries; $\mathrm{RCl}$ : right common iliac artery; REl: distal right external iliac artery).

- Tab. 3 Vergleich des Gefäßsignals zwischen den 40 keV-VMI des DLCT und den konventionellen Bildern des SLCT (AA: Aorta ascendens auf Höhe der rechten Pulmonalarterie; DA: Aorta descendens auf Höhe der rechten Pulmonalarterie; HA: Aorta auf Höhe des Zwerchfelldurchtritts; RA: Aorta auf Höhe der Nierenarterien; RCl: Arteria iliaca communis rechts; REl: distale Arteria iliaca externa rechts).

\begin{tabular}{|l|l|l|l|}
\hline $\begin{array}{l}\text { Attenua- } \\
\text { tion }\end{array}$ & DLCT $(\mathbf{4 0} \mathbf{k e V})$ & SLCT & p-value \\
\hline AA & $537.5 \pm 184$ & $469.8 \pm 168$ & $<0.01$ \\
\hline AD & $583.4 \pm 205$ & $503.8 \pm 183$ & $<0.01$ \\
\hline HA & $572.5 \pm 224$ & $475.4 \pm 191$ & $<0.01$ \\
\hline RA & $609.5 \pm 244$ & $499.2 \pm 215$ & $<0.01$ \\
\hline RCI & $616.2 \pm 282$ & $499.2 \pm 232$ & $<0.01$ \\
\hline REI & $655.7 \pm 306$ & $532.2 \pm 271$ & $<0.01$ \\
\hline Total & $589.6 \pm 243$ & $492.7 \pm 209$ & $<0.01$ \\
\hline
\end{tabular}

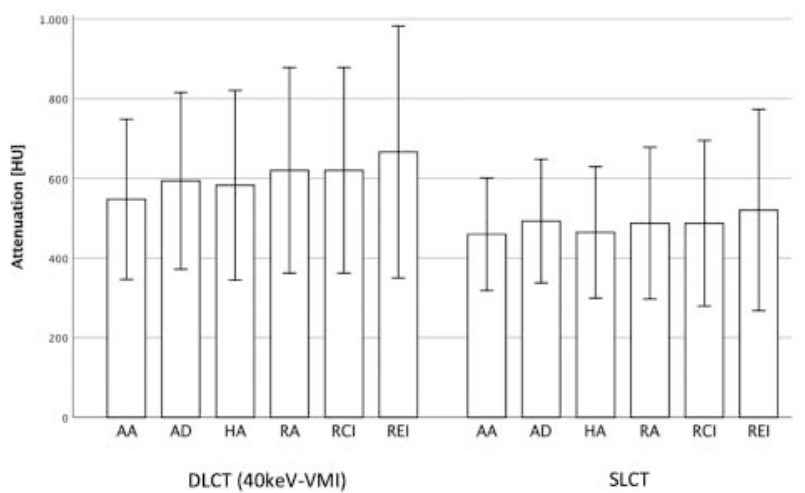

- Fig. 3 Attenuation of $40 \mathrm{keV}$-VMI of DLCT across the arterial segments compared with conventional SLCT images (AA: ascending aorta at the level of the right pulmonary artery; DA: descending aorta at the level of the right pulmonary artery; HA: aorta at the level of hiatus; RA: aorta at the level of the renal arteries; RCI: right common iliac artery; REl: distal right external iliac artery).

- Abb. 3 Vergleich des Gefäßsignals entlang der arteriellen Zugangsachse zwischen den $40 \mathrm{keV}$-VMI des DLCT und den konventionellen Bildern des SLCT (AA: Aorta ascendens auf Höhe der rechten Pulmonalarterie; DA: Aorta descendens auf Höhe der rechten Pulmonalarterie; HA: Aorta auf Höhe des Zwerchfelldurchtritts; RA: Aorta auf Höhe der Nierenarterien; RCI: Arteria iliaca communis rechts; REl: distale Arteria iliaca externa rechts).

In the separate comparison of the DLCT group with the SLCT group at $100 \mathrm{kV}$ and $120 \mathrm{kV}$, similar trends were observed without reaching the level of statistical significance ( $\triangleright$ Table 6 ). Between
- Table 4 Signal-to-noise ratio (SNR) and contrast-to-noise ratio (CNR) of $40 \mathrm{keV}$-VMI of DLCT and SLCT (AA: ascending aorta at the level of the right pulmonary artery; DA: descending aorta at the level of the right pulmonary artery; $\mathrm{HA}$ : aorta at the level of hiatus; $\mathrm{RA}$ : aorta at the level of the renal arteries; $\mathrm{RCl}$ : right common iliac artery; REl: distal right external iliac artery).

- Tab. 4 Signal-Rausch-Verhältnis (SNR) und Kontrast-Rausch-Verhältnis (CNR) der 40 keV-VMI des DLCT im Vergleich zu den konventionellen Bildern des SLCT (AA: Aorta ascendens auf Höhe der rechten Pulmonalarterie; DA: Aorta descendens auf Höhe der rechten Pulmonalarterie; HA: Aorta auf Höhe des Zwerchfelldurchtritts; RA: Aorta auf Höhe der Nierenarterien; RCI: Arteria iliaca communis rechts; REl: distale Arteria iliaca externa rechts).

\begin{tabular}{|l|l|l|l|}
\hline SNR & DLCT (40 keV) & SLCT & p-value \\
\hline AA & $26.3 \pm 11$ & $21.6 \pm 9$ & $<0.01$ \\
\hline AD & $29.1 \pm 11$ & $23.5 \pm 10$ & $<0.01$ \\
\hline HA & $18.3 \pm 7$ & $15.5 \pm 6$ & $<0.01$ \\
\hline RA & $21.6 \pm 9$ & $18.0 \pm 8$ & $<0.01$ \\
\hline RCI & $21.2 \pm 10$ & $16.7 \pm 7$ & $<0.01$ \\
\hline REI & $28.8 \pm 38$ & $18.7 \pm 9$ & $<0.01$ \\
\hline Total & $23.6 \pm 18$ & $18.6 \pm 9$ & $<0.01$ \\
\hline CNR & DLCT (40 keV) & SLCT & p-value \\
\hline AA & $23.1 \pm 10$ & $21.6 \pm 9$ & $<0.01$ \\
\hline AD & $25.9 \pm 10$ & $20.8 \pm 9$ & $<0.01$ \\
\hline HA & $16.2 \pm 7$ & $13.6 \pm 6$ & $<0.01$ \\
\hline RA & $19.3 \pm 9$ & $15.9 \pm 7$ & $<0.01$ \\
\hline RCI & $19.0 \pm 10$ & $14.8 \pm 7$ & $<0.01$ \\
\hline REI & $26.5 \pm 38$ & $16.5 \pm 9$ & $<0.01$ \\
\hline Total & $21.1 \pm 18$ & $16.4 \pm 8$ & $<0.01$ \\
\hline & & & \\
\hline
\end{tabular}

the two SLCT groups, the measured values for attenuation, SNR and CNR were higher when using $100 \mathrm{kV}$.

\section{Radiation dose}

The total dose length product of the complete TAVI planning examination was significantly lower in the DLCT group $\left(1994 \pm 367 \mathrm{mGy}^{*} \mathrm{~cm}\right.$, including the ECG-gated acquisition of the heart) compared to the SLCT group $\left(2439 \pm 703 \mathrm{mGy}^{*} \mathrm{~cm}\right.$; $\mathrm{p}<0.01)$. The same tendencies were found in the two subgroups of patients with a BMI below and above $25 \mathrm{~kg} / \mathrm{m} 2$ with significantly lower total dose length products in both DLCT groups (BMI<25: $1864 \pm 293$ mGy* cm vs. $2363 \pm 694 \mathrm{mGy}^{*} \mathrm{~cm} ; \mathrm{BMl}>25$ : $2093 \pm 393 \mathrm{mGy}^{*} \mathrm{~cm}$ vs. $2720 \pm 610 \mathrm{mGy}$ mGy* $\left.{ }^{*} \mathrm{~cm} ; \mathrm{p}<0.001\right)$.

The volume CT dose index (CTDIvol) of the SLCT group was $33.4 \pm 9 \mathrm{mGy}$. The CTDIvol in the DLCT group was $48.2 \pm 9 \mathrm{mGy}$ for the ECG-gated heart imaging and $10.9 \pm 3 \mathrm{mGy}$ for the nonECG-gated high-pitch spiral CTA. 
- Table 5 Noise across the arterial segments of $40 \mathrm{keV}$-VMI of DLCT and SLCT (AA: ascending aorta at the level of the right pulmonary artery; DA: descending aorta at the level of the right pulmonary artery; HA: aorta at the level of hiatus; RA: aorta at the level of the renal arteries; $\mathrm{RCl}$ : right common iliac artery; REl: distal right external iliac artery).

- Tab. 5 Vergleich des Rauschens entlang der arteriellen Zugangsachse zwischen den $40 \mathrm{keV}$-VMI des DLCT und den konventionellen Bildern des SLCT (AA: Aorta ascendens auf Höhe der rechten Pulmonalarterie; DA: Aorta descendens auf Höhe der rechten Pulmonalarterie; HA: Aorta auf Höhe des Zwerchfelldurchtritts; RA: Aorta auf Höhe der Nierenarterien; RCI: Arteria iliaca communis rechts; REl: distale Arteria iliaca externa rechts).

\begin{tabular}{|l|l|l|l|}
\hline Noise & DLCT $(\mathbf{4 0} \mathbf{k e V})$ & SLCT & p-value \\
\hline AA & $21.6 \pm 6$ & $22.7 \pm 5$ & 0.218 \\
\hline AD & $20.7 \pm 5$ & $22.7 \pm 6$ & 0.027 \\
\hline HA & $32.3 \pm 7$ & $32.1 \pm 8$ & 0.895 \\
\hline RA & $29.5 \pm 8$ & $29.3 \pm 8$ & 0.883 \\
\hline RCI & $30.9 \pm 8$ & $30.5 \pm 7$ & 0.763 \\
\hline REI & $29.3 \pm 9$ & $28.7 \pm 9$ & 0.682 \\
\hline Total & $27.8 \pm 9$ & $28.1 \pm 8$ & 0.599 \\
\hline
\end{tabular}

\section{Discussion}

To our knowledge, this is the first study to compare the objective image quality of CTA prior to TAVI between a first-generation dual-layer spectral CT scanner and a conventional single-layer CT scanner. In this study, we demonstrated that not only using DLCT is feasible for TAVI planning but also provides in general higher objective image quality and lower radiation dose compared with SLCT.

These results were achieved despite the late arterial phase caused by the limited detector width of the first generation DLCT. A narrow detector width requires a split-phase protocol for TAVI imaging with a short delay between these two scans. As discussed in the introduction section, the delayed second scan and the resulting late arterial phase affects the image quality and results in a loss of vessel enhancement. However, reconstruction of $\mathrm{VMI}$ at $40 \mathrm{keV}$ is known to increase vessel attenuation and this approach was chosen in our study [10-13]. By using VMI at a low keV level near the k-edge of iodine (33 keV), we observed a significant increase in vessel attenuation, SNR, and CNR compared with SLCT. This observation is especially valid regarding the comparison with the SLCT acquisitions performed at $120 \mathrm{kV}$. Concerning the small subgroup of SLCT acquisitions performed at $100 \mathrm{kV}$, the superiority of low-keV VMI was generally not statistically significant. This is supposed to result from the fact that reducing the tube voltage from $120 \mathrm{kV}$ to $100 \mathrm{kV}$ already leads to a relevant increase in iodine-induced CT attenuation. Our results are in line with numerous other studies that have shown the benefits of DLCT and monoenergetic imaging $[10,11]$.

Especially in examinations with poor vascular contrast, DLCT has advantages, since the spectral data set is available in every CT scan. A study by Hickethier and colleagues demonstrated that, with the help of monoenergetic image reconstruction, even the contrast in a venous contrast phase is sufficient to allow adequate vascular assessment of abdominal arteries [11]. Weiss and colleagues demonstrated the improvement of monoenergetic image reconstructions for the detection of incidental pulmonary embolism in scans during the portal-venous phase [14].

Our study results suggest that a TAVI planning protocol with a reduced contrast dose also seems possible with DLCT. A promising approach is offered by the prospective SPECTACULAR study by Cavallo and colleagues [15].

In their study, a low-dose contrast agent protocol and $40 \mathrm{keV}$ VMI of DLCT were chosen for TAVI planning. They also chose a split protocol, but with an abdominal acquisition during an arteriovenous mixed phase following a retrospective ECG-triggered chest scan during an arterial phase [15]. Adequate results in terms of image quality and aortic root measurements were obtained with only $50 \mathrm{ml}$ of contrast medium [15]. However, most of their conclusions were based on the comparison with conventional images at $120 \mathrm{kV}$ of the same scan. Using this method, the improvement of image quality with $40 \mathrm{keV}-\mathrm{VMI}$ is well established in the literature and is in line with our results $[11,12,16]$.

We also achieved a $17 \%$ reduction in radiation dose when comparing these two scanners and protocols. This demonstrates that low radiation dose can be achieved even with DLCT when adapted examination protocols are used. It should be mentioned that we had chosen a radiation-intensive protocol with SLCT, which was considered in the guidelines at that time, but is no longer recommended in the current guidelines $[6,8]$.

There are other studies on differing examination protocols, such as the 3-phase protocol, that have achieved promising results regarding radiation and contrast agent reduction $[17,18]$.

There are several limitations to this study. First, the slice thickness and increment were not identical between SLCT and DLCT image data sets. The slice thickness affects image noise and, thus, calculation of the SNR. If SLCT would have been reconstructed with the same slice thickness as DLCT, image noise would decrease to some degree. However, since the calculation of the CNR is unaffected by variations in image noise within the same data set, and the CNR of DLCT was superior to SLCT in our study, the impact of the inequality of slice thicknesses on the results is considered marginal. Second, the algorithm of iterative image reconstruction was not identical between the SLCT and DLCT image data sets. SLCT image data were reconstructed using IMR. DLCT spectral data had to be reconstructed using iDose4, as provided by the vendor. Other studies have shown that IMR may be more effective in noise reduction than iDose4 [19-21]. Thus, this discrepancy will tend to result in an underestimation of the superiority of DLCT concerning the SNR. Third, we focused on assessing parameters of objective image quality of the aortic CTA. Subjective image quality included assessment of the general evaluability of the aortic CTA, assessment of the heart and the left ventricular outflow tract as well as assessment of the presence and severity of stenoses along the iliac access route. In this regard it has to be acknowledged that low-keV image reconstructions may lead to overestimation of calcified stenoses. Fourth, we limited the study to the assessment of VMI at an energy level of $40 \mathrm{keV}$, because this has been previously shown to be best for 
- Table 6 Comparison of attenuation, signal-to-noise ratio (SNR), contrast-to-noise ratio (CNR), and noise of the DLCT group with the SLCT subgroup at $100 \mathrm{kV}$ and $120 \mathrm{kV}$ (AA: ascending aorta at the level of the right pulmonary artery; DA: descending aorta at the level of the right pulmonary artery; HA: aorta at the level of hiatus; RA: aorta at the level of the renal arteries; RCI: right common iliac artery; REI: distal right external iliac artery).

- Tab. 6 Vergleich des Gefäßsignals, des Signal-Rausch-Verhältnisses (SNR), des Kontrast-Rausch-Verhältnisses (CNR) und des Rauschens der 40 keVVMI des DLCT mit den Subgruppen des SLCT bei 100 kV und 120 kV (AA: Aorta ascendens auf Höhe der rechten Pulmonalarterie; DA: Aorta descendens auf Höhe der rechten Pulmonalarterie; HA: Aorta auf Höhe des Zwerchfelldurchtritts; RA: Aorta auf Höhe der Nierenarterien; RCl: Arteria iliaca communis rechts; REl: distale Arteria iliaca externa rechts).

\begin{tabular}{|c|c|c|c|c|c|}
\hline Attenuation & DLCT (40 keV, n= 75) & SLCT (100 kV, n= 26) & SLCT (120 kV, n= 49) & p-value (40 vs. $100 \mathrm{kV})$ & p-value (40 vs. $120 \mathrm{kV})$ \\
\hline AA & $537.5 \pm 184$ & $494.7 \pm 161$ & $440.5 \pm 128$ & 0.246 & $<0.01$ \\
\hline$A D$ & $583.4 \pm 205$ & $534.2 \pm 178$ & $470.5 \pm 138$ & 0.161 & $<0.01$ \\
\hline HA & $572.5 \pm 224$ & $497.7 \pm 189$ & $446.3 \pm 150$ & 0.175 & $<0.01$ \\
\hline RA & $609.5 \pm 244$ & $520.5 \pm 225$ & $469.8 \pm 169$ & 0.454 & $<0.01$ \\
\hline $\mathrm{RCl}$ & $616.2 \pm 282$ & $528.6 \pm 240$ & $465.1 \pm 188$ & 0.352 & $<0.01$ \\
\hline REI & $655.7 \pm 306$ & $572.1 \pm 300$ & $492.9 \pm 221$ & 0.388 & $<0.01$ \\
\hline SNR & DLCT (40 keV, n= 75) & SLCT (100 kV, n= 26) & SLCT (120 kV, n= 49) & p-value (40 vs. $100 \mathrm{kV})$ & p-value ( 40 vs. $120 \mathrm{kV})$ \\
\hline AA & $26.3 \pm 11$ & $23.7 \pm 10$ & $19.8 \pm 6$ & 0.383 & $<0.01$ \\
\hline AD & $29.1 \pm 11$ & $26.2 \pm 10$ & $21.2 \pm 8$ & 0.448 & $<0.01$ \\
\hline HA & $18.3 \pm 7$ & $16.5 \pm 7$ & $14.6 \pm 6$ & 0.527 & 0.074 \\
\hline RA & $21.6 \pm 9$ & $19.2 \pm 9$ & $17.1 \pm 7$ & 0.439 & 0.014 \\
\hline $\mathrm{RCI}$ & $21.2 \pm 10$ & $18.2 \pm 7$ & $15.5 \pm 7$ & 0.019 & $<0.01$ \\
\hline REI & $28.8 \pm 38$ & $20.1 \pm 9$ & $17.6 \pm 9$ & 0.194 & 0.07 \\
\hline CNR & DLCT (40 keV, n= 75) & SLCT $(100 \mathrm{kV}, \mathrm{n}=26)$ & SLCT (120 kV, n= 49) & p-value (40 vs. $100 \mathrm{kV})$ & p-value (40 vs. $120 \mathrm{kV})$ \\
\hline AA & $23.1 \pm 10$ & $20.9 \pm 9$ & $17.2 \pm 6$ & 0.401 & $<0.01$ \\
\hline$A D$ & $25.9 \pm 10$ & $23.3 \pm 9$ & $18.6 \pm 7$ & 0.457 & 0.007 \\
\hline HA & $16.2 \pm 7$ & $14.6 \pm 6$ & $12.7 \pm 5$ & 0.517 & 0.066 \\
\hline RA & $19.3 \pm 9$ & $17.1 \pm 9$ & $15.0 \pm 7$ & 0.392 & 0.007 \\
\hline $\mathrm{RCl}$ & $19.0 \pm 10$ & $16.1 \pm 7$ & $13.6 \pm 6$ & 0.036 & $<0.01$ \\
\hline REI & $26.5 \pm 38$ & $17.9 \pm 9$ & $15.5 \pm 8$ & 0.199 & 0.064 \\
\hline Noise & DLCT (40 keV, n= 75) & SLCT (100 kV, n= 26) & SLCT (120 kV, n= 49) & p-value (40 vs. $100 \mathrm{kV})$ & p-value (40 vs. $120 \mathrm{kV})$ \\
\hline AA & $21.6 \pm 6$ & $22.0 \pm 6$ & $23.1 \pm 5$ & 0.665 & 0.720 \\
\hline AD & $20.7 \pm 5$ & $21.2 \pm 4$ & $23.5 \pm 7$ & 0.634 & 0.091 \\
\hline HA & $32.3 \pm 7$ & $31.2 \pm 6$ & $32.4 \pm 9$ & 0.631 & 0.177 \\
\hline RA & $29.5 \pm 8$ & $28.8 \pm 8$ & $29.4 \pm 9$ & 0.761 & 0.369 \\
\hline $\mathrm{RCl}$ & $30.9 \pm 8$ & $29.3 \pm 7$ & $31.1 \pm 7$ & 0.412 & 0.204 \\
\hline REI & $29.3 \pm 9$ & $29.6 \pm 8$ & $28.0 \pm 9$ & 0.413 & 0.535 \\
\hline
\end{tabular}

the contrast and visualization of vascular structures [10,11]. Finally, this was a retrospective study with image quality assessments performed by a single reader. A multi-reader analysis may have fortified the robustness of the study results.

\section{Conclusion}

In conclusion, performing TAVI planning with a dual-layer spectral detector CT scanner using a split-phase protocol is feasible when using low-energy VMI at $40 \mathrm{keV}$ for late arterial aortic CTA. Higher objective image quality with a lower radiation dose was obtained compared to ECG-synchronized CTA of the whole aorta performed with conventional CT.

Further research is required to evaluate if contrast volume reduction using DLCT with reconstruction of low-energy images is feasible without hampering image quality.

\section{Conflict of Interest}

The authors declare that they have no conflict of interest. 


\section{References}

[1] Fornaro J, Leschka S, Hibbeln D et al. Dual- and multi-energy CT: approach to functional imaging. Insights Imaging 2011; 2: 149-159. doi:10.1007| s13244-010-0057-0

[2] Johnson TR. Dual-energy CT: general principles. Am J Roentgenol 2012; 199: S3-S8. doi:10.2214/Am J Roentgenol.12.9116

[3] Rassouli N, Etesami M, Dhanantwari A et al. Detector-based spectral CT with a novel dual-layer technology: principles and applications. Insights into Imaging 2017; 8: 589-598. doi:10.1007/s13244-017-0571-4

[4] McCollough CH, Leng S, Yu L et al. Dual- and Multi-Energy CT: Principles, Technical Approaches, and Clinical Applications. Radiology 2015; 276: 637-653. doi:10.1148/radiol.2015142631

[5] Abbara S, Blanke P, Maroules CD et al. SCCT guidelines for the performance and acquisition of coronary computed tomographic angiography: A report of the Society of Cardiovascular Computed Tomography Guidelines Committee. Journal of Cardiovascular Computed Tomography 2016; 10: 435-449. doi:10.1016/j.jcct.2016.10.002

[6] Achenbach S, Delgado V, Hausleiter J et al. SCCT expert consensus document on computed tomography imaging before transcatheter aortic valve implantation (TAVI)/transcatheter aortic valve replacement (TAVR). J Cardiovasc Comput Tomogr 2012; 6: 366-380. doi:10.1016 j.jcct.2012.11.002

[7] Blanke P, Schoepf UJ, Leipsic JA. CT in Transcatheter Aortic Valve Replacement. Radiology 2013; 269: 650-669. doi:10.1148/radiol.13120696

[8] Blanke P, Weir-McCall JR, Achenbach S et al. Computed tomography imaging in the context of transcatheter aortic valve implantation (TAVI)/ transcatheter aortic valve replacement (TAVR): An expert consensus document of the Society of Cardiovascular Computed Tomography. J Cardiovasc Comput Tomogr 2019; 13: 1-20. doi:10.1016/j. jcct.2018.11.008

[9] Shuman WP, O’Malley RB, Busey JM et al. Prospective comparison of dualenergy CT aortography using 70\% reduced iodine dose versus singleenergy CT aortography using standard iodine dose in the same patient. Abdominal Radiology 2017; 42: 759-765. doi:10.1007/s00261-0161041-z

[10] Doerner J, Hauger M, Hickethier T et al. Image quality evaluation of duallayer spectral detector CT of the chest and comparison with conventional CT imaging. European Journal of Radiology 2017: 52-58. doi:10.1016/ j.ejrad.2017.05.016

[11] Hickethier T, Byrtus ], Hauger M et al. Utilization of virtual mono-energetic images (MonoE) derived from a dual-layer spectral detector CT (SDCT) for the assessment of abdominal arteries in venous contrast phase scans. Eur J Radiol 2018; 99: 28-33. doi:10.1016/j.ejrad.2017.12.007
[12] Chalian H, Kalisz K, Rassouli N et al. Utility of virtual monoenergetic images derived from a dual-layer detector-based spectral CT in the assessment of aortic anatomy and pathology: A retrospective case control study. Clin Imaging 2018; 52: 292-301. doi:10.1016/ j.clinimag.2018.08.007

[13] Al-Baldawi Y, Große Hokamp N, Haneder S et al. Virtual mono-energetic images and iterative image reconstruction: abdominal vessel imaging in the era of spectral detector CT. Clin Radiol 2020; 75: 641.e649-641. e618. doi:10.1016/j.crad.2020.03.036

[14] Weiss ], Notohamiprodjo M, Bongers M et al. Effect of Noise-Optimized Monoenergetic Postprocessing on Diagnostic Accuracy for Detecting Incidental Pulmonary Embolism in Portal-Venous Phase Dual-Energy Computed Tomography. Invest Radiol 2017; 52: 142-147. doi:10.1097| RLI.0000000000000319

[15] Cavallo AU, Patterson AJ, Thomas R et al. Low dose contrast CT for transcatheter aortic valve replacement assessment: Results from the prospective SPECTACULAR study (spectral CT assessment prior to TAVR). J Cardiovasc Comput Tomogr 2019. doi:10.1016/j.jcct.2019.06.015

[16] Van Hamersvelt RW, Eijsvoogel NG, Mihl C et al. Contrast agent concentration optimization in CTA using low tube voltage and dual-energy CT in multiple vendors: a phantom study. The International Journal of Cardiovascular Imaging 2018; 34: 1265-1275. doi:10.1007/s10554-0181329-x

[17] Koyanagi H, Tsutsumi Y, Tokuda Y et al. Computed tomography imaging using split-bolus contrast injection with volume scan of aortic root and heart for preoperative evaluation of transcatheter aortic valve implantation. Heart Vessels 2021. doi:10.1007/s00380-021-01899-8

[18] Shnayien S, Bressem KK, Beetz NL et al. Radiation Dose Reduction in Preprocedural CT Imaging for TAVI/TAVR Using a Novel 3-Phase Protocol: A Single Institution's Experience. Rofo 2020; 192: 1174-1182. doi:10.1055/ a-1150-7646

[19] Ippolito D, Riva L, Talei Franzesi C et al. Computed Tomography Angiography Combined With Knowledge-Based Iterative Algorithm for Transcatheter Aortic Valve Implantation Planning: Image Quality and Radiation Dose Exposure With Low-kV and Low-Contrast-Medium Protocol. J Comput Assist Tomogr 2020; 44: 13-19. doi:10.1097/rct.0000000000000965

[20] Laqmani A, Avanesov M, Butscheidt S et al. Comparison of image quality and visibility of normal and abnormal findings at submillisievert chest CT using filtered back projection, iterative model reconstruction (IMR) and iDose(4) ${ }^{\mathrm{TM}}$. Eur J Radiol 2016; 85: 1971-1979. doi:10.1016/ j.ejrad.2016.09.001

[21] Park H], Lee JM, Park SB et al. Comparison of Knowledge-based Iterative Model Reconstruction and Hybrid Reconstruction Techniques for Liver CT Evaluation of Hypervascular Hepatocellular Carcinoma. Journal of computer assisted tomography 2016; 40: 863-871. doi:10.1097/ rct.0000000000000455 